\title{
LOS GRUPOS TERRITORIALES DEL SENADO *
}

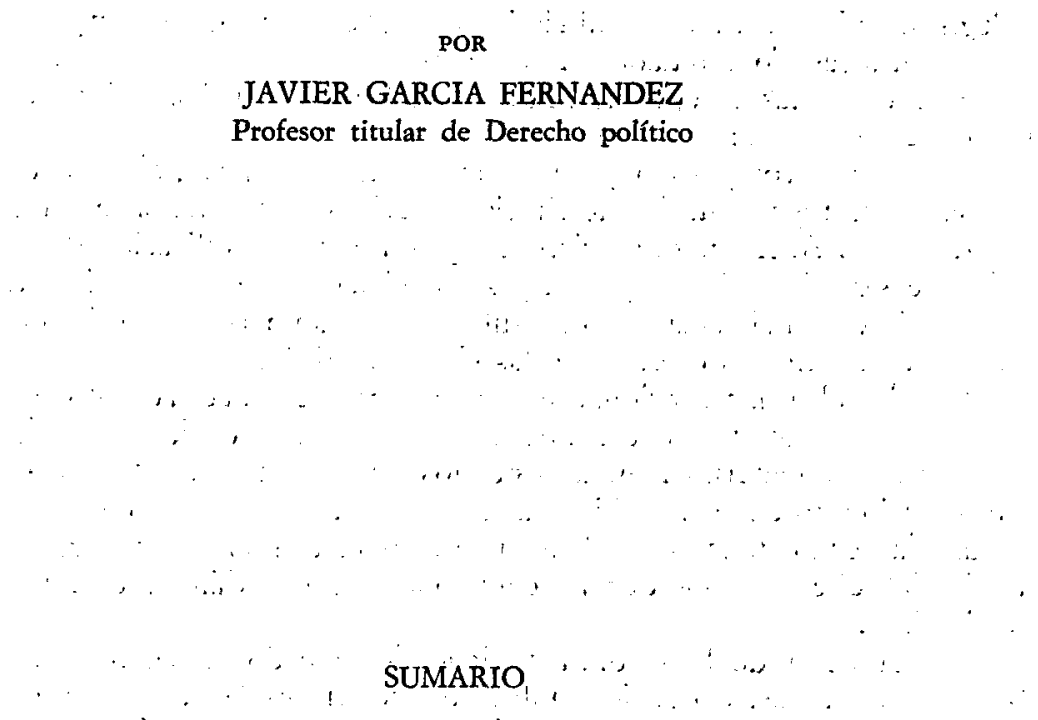

1. El' Senado como Cámara de REPREsentación terRitórial-2. ORIgein parlamentario de los 'Grupos Territoriales. - 3. Naturaleza jurídica de los Grupos. - 4. Funciones de los Grupos Parlamentarios.-5. Los GRUPOS Territoriales y. la articulación autonómica deL Senado.-6.. Conclustón.

\section{EL SENADO COMO CAMARA DE REPRESENTACION TERRITORIAL}

En pocos órganos constitucionales se detecta mayor unanimidad de la doctrina como en el Senado. Con excepciones significadas, pero escasas, la mayoría de los constitucionalistas han coincidido en resaltar su estructura y composición atípicas, su falta de protagonismo político y legislativo y, lo que es más importante, su incapacidad para ejercer funciones específicas de representación territorial. Desde una posición de lege lata, solamente Andrea Manzella ha valorado la importancia del Senado como garantía constitucional contra el centralismo, aun reconociendo la preeminencia del Congreso en las materias más propias del Senado, que serían las relacionadas con las Comunidades Autónomas ${ }^{1}$. $Y$ desde una posición de lege ferenda, los profesores Aja y Arbós, admitiendo igualmente las limitadas facultades de la Cámara y su no mayor peso político, proponen mecanismos para dotarla de mayor representatividad

* Comunicación presentada a las I Jornadas de Derecho Parlamentario organizadas por el Congreso de los Diputados y celebradas en Madrid los días 21 a 23 de marzo de 1984. Deseo agradecer al profesor don Pablo Lucas Murillo la lectura del texto y las numerosas observaciones que hizo al mismo, aunque la responsabilidad de las ideas que se vierten es exclusivamente del autor.

${ }_{1}$ Andrea Manzella, «Las Cortes en el sistema constitucional español», en Alberto Predieri y Eduardo García de Enterría (coords.), La Constitución española de 1978. Estudio sistemático, Madrid, Civitas, 1980, espec. págs. 460-463. 
y legitimidad a partir de la dinámica que puedan crear los senadores que representan a las Comunidades Autónomas ${ }^{2}$.

Pero con estas excepciones, hay unanimidad en la doctrina en torno a los siguientes extremos:

a) Por su composición, mayoritariamente provincial, el Senado no puede expresar una representación territorial especial del tipo de las Segundas Cámaras federales. Antes bien, su circunscripción es una duplicación de la del Congreso de los Diputados, cuyos rasgos esenciales no se ven desvirtuados por la utilización de un sistema electoral diferente ni tampoco por la limitada presencia de representantes directos de las Comunidades ${ }^{3}$.

b) En el orden funcional, el Senado aparece supeditado al Congreso a lo largo del procedimiento legislativo, y la mínima prevalencia de la Segunda Cámara en las materias reguladas por los artículos $145.2,155.1$ y 158.2 de la Constitución no empaña la idea básica de que es el Congreso el que tiene atribuidas las competencias fundamentales, en el campo de la descentralización territorial, que es el que debería corresponder a una Cámara de representación territorial ${ }^{4}$.

c) A pesar de la absoluta paridad del Senado respecto a determinadas materias (tratados, convenios, aplicación del título II) en la hipótesis de un conflicto entre las dos Cámaras, el Congreso tiene atribuida la potestad de resolverlo con una posición subordinada de la Segunda Cámara ${ }^{5}$.

Estas opiniones, prácticamente unánimes en la doctrina, nos eximen de profundizar más en torno a la naturaleza del Senado que, a los efectos de la presente comunicación, posee dos rasgos definitorios, a saber: que se trata de una Cámara depreciada y que su provincialización impide que pueda actuar en una dinámica territorial $\mathrm{y}$, por ende, descentralizadora ${ }^{6}$. No es por ello

2 Eliseo Aja y Xabier Arbos, «El Senado, Cámara posible de las autonomías», en Revista de Estudios Políticos, núm. 17, sept.-oct. 1980, págs. 27-66.

3 J. A. Portero, «El Senado en la Constitución española», en M. Ramírez (ed.), Estudios sabre la Constitución española de 1978, Zaragoza, Pórtico, 1979, págs. 217-234; L. Aguilo Lucía, "Composición y organización de las Cortes», en el vol. col. Estudios sobre la Constitución española de 1978, Valencia, Secretariado de Publicaciones de la Universidad de Valencia, 1980, págs. 301-312; E. Recoder de Casso, "Artículo 69», en F. Garrido Falla (ed.), Comentarios a la Constitución, Madrid, Civitas, 1980, págs. 730-738; P. Lucas Murillo, «Los órganos constitucionales», en A. de Blas (comp.), Introducción al sistema político español, Barcelona, Teide, 1983, págs. 107-251. Para el concepto de representación especial, en su proyección territorial, véase $R$. Punset, «El concepto de representación territorial en la Constitución española de 1978», en Revista del Departamento de Derecho Político, UNED, núm. 7, otoño 1980, págs. 105-118.

${ }_{4}$ M. Gonzalo, «Posición de las Cortes Generales en la Constitución», en T. R. Fernández (coord.), Lecturas sobre la Constitución española, vol. II, Madrid, UNED, 1978, págs. 639-765; Portero, op. cit.; Manzella, op. cit., J. A. Santamaría Pastor, "Artículo 89», en Garrido Falla (ed.), Comentarios..., cit., págs. 899-902; M. Martínez Sospedra, Aproximación al Derecho Constitucional español. La Constitución de 1978, Valencia, Fernando Torres Ed., 1980, págs. 140-144; Lucas Murillo, op. cit.; E. Alvarez Conde, El régimen político español, Madrid, Tecnos, 1983, págs. 127-132 y 177-181.

${ }^{5}$ Recoder de Casso, «Artículo 74.2", en Garrido Falla, op. cit., págs. 791-795; Santamaría Pastor, «Artículo 90», en Garrido Falla, op. cit., págs. 903-912.

- Véase J. Elizalde, «El Senado como Cámara de representación territorial en el Estado autonómico: una perspectiva comparada», en Revista de Política Comparada, núm. 6, otoño 1981, págs. 195-228, con interesantes consideraciones sobre la dinámica política de las Segundas Cámaras. 
extraño que algún autor propugne la revisión constitucional para rectificar esta atípica configuración ${ }^{7}$.

Pero desde la aprobación del Reglamento del Senado, en 1982; se ha abierto una posible vía que podría llevar a rectificar la dinámica, nada territorialista, de la Cámara, a fin de que la reducida representación directa que se ha atribuido a las Comunidades Autónomas pueda alcanzar mayor protagonismo e influencia en este. Senado provincial. Se trata de los Grupos Parlamentarios Territoriales, cuya creación está prevista en los artículos 32' y 33 del Reglamento y cuya creación ha ido generalizándose paulatinamente ${ }^{8}$. ¿Pueden estos Grupos potenciar la limitada proyección territorial de la Cámara? ¿Qué sentido tienen en un sistema político de partidos que hace prácticamente imposible la concurrencia electoral de otras formaciones sociales y culturales incluso en un régimen predominantemente mayoritario como es el del Senado? Puede decirse que estamos ante un instituto parlamentario atípico cuyo alcance político y sus rasgos jurídicos conviene examinar. $\therefore$

\section{ORIGEN PARLAMENTARIO DE LOS GRUPOS TERRITORIALES}

El Proyecto de Reglamento que se presentó a la Cámara en julio de 1980 contenía ya en sus rasgos sustanciales la regulación de los Grupos Territoriales que ahora existen, pero aquella redacción presentaba algunos matices de interés que conviene recordar. Estas diferencias consistían, en primer lugar, en que el requisito de procedencia de los senadores se elevaba en sús orígenes a tres Comunidades Autónomas. En segundo lugar, el Proyecto no exigía, en su artículo 33, que la notificación de constitución del Grupo cursada a la Presidencia de la Cámara contuviera referencia expresa al territorio y al partido (o federación, coalición o agrupación) al que pertenecían sus componentes, como prevé el Reglamento vigente. En tercer lugar, por último, el representante del Grupo ténía la denominación expresa de portavoz?.

Las enmiendas presentadas a los artículos 32 y 33 se orientaban en cuatro direcciones divergentes:

a) Las que proponían meras mejoras técnicas, casi exigidas por la lógica: enmiendas número 38, del senador Casademont Perafita (Senadores Vascos), y 166, del Grupo de Senadores Vascos, que sugerían reducir a dos el número de Comunidades Autónomas, de donde debían proceder los senadores integrantes de un Grupo Parlamentario para legitimar la petición de Grupo Territorial ${ }^{10}$.

7 Como, por ejemplo, F. Fernández Segado, «El bicameralismo y la naturaleza del Senadò», en Revista Española de Derecho Constitucional, núm. 6, septiembre-diciembre 1982, págs. 61-113.

${ }_{8}$ El primer Grupo Territorial que se constituyó fue el Popular Castellano-Leonés, formado por trece senadores, cuya constitución fue notificada al presidente de la Cámara, con fecha 8 de marzo de 1983. Posteriormente se han creado todos los restantes Grupos.

- Boletín Oficial de las Cortes Españolas. I. Legislatura, núm. 13 (a), 8 de julio de 1980.

${ }_{10}$ Todas las enmiendas se encuentran recogidas en el núm. 13 (c), de 19 septiembre 1980, del BOCE, Senado, I Legislatura. En el núm. 18-19 de la Revista de Derecho Poli- 
b) Las que buscaban establecer una separación absoluta entre Grupos Territoriales y Grupos Parlamentarios de configuración partidaria, de modo que a cada Comunidad Autónoma correspondiera un Grupo Territorial: enmiendas números 36 y 52, de los senadores Benet Morell (adscrito a Senadores Vascos) y Portabella i Ráfols (Grupo Mixto).

c) Las que pretendían acentuar la autonomía de los Grupos Territoriales respecto a los Grupos Parlamentarios de donde procedian: enmiendas números 5 a 10, del senador Bosque Hita (Grupo Mixto).

d) Las que; por el contrario, intentaban destacar la vinculación y subordinación de los Grupos Territoriales con respecto a los Grupos Parlamentarios: enmiendas números 268 y 269 , del Grupo de UCD.

e) En fin, las que proponían la supresión de estos nuevos Grupos: enmiendas números 118 y 119 , del Grupo Parlamentario Socialista Andaluz, y 344, del senador Fombuena Escudero (Grupo Parlamentario de UCD).

La Ponencia recondujo estas propuestas en una sola dirección, que respondía a la del partido mayoritario en la Cámara (UCD), de modo que sólo estimó las enmiendas de este partido. De esta forma, el Pleno conoció una regulación todavía más restrictiva para la autonomía de los Grupos Territoriales, que dejaron de tener portavoces para asignárseles solamente un representante, y la nueva redacción vinculó su notificación de constitución a la referencia expresa al partido al que perteneciesen sus miembros. En cambio, en este trámite parlamentario se flexibilizó el requisito del origen territorial de estos senadores, que se redujo a dos Comunidades Autónomas ${ }^{11}$. Posteriormente, la Comisión no introdujo el menor cambio a lo que había dictaminado la Ponencia ${ }^{12}$.

En la discusión en el Pleno, las distintas intervenciones aportan algunas ideas complementarias para conocer cómo la mayoría parlamentaria configuró estos Grupos. Por parte de UCD, los senadores Calatayud Maldonado (que representaba a la Ponencia) y Enciso Recio destacaron que la conexión entre la Cámara y la representación política se realiza principalmente a través de los Grupos políticos o «ideológicos», y sólo en el seno de estos Grupos se pueden configurar Grupos Territoriales. La finalidad de éstos, para el senador Enciso Recio, tiene, en cierto modo, una naturaleza beligerante contra los partidos nacionalistas o regionales, que consiste en atribuir a los partidos de representación estatal un cauce de actuación parlamentario más volcado en problemas de incidencia local, que, de lo contrario, estaría monopolizado por los partidos nacionalistas. Ello no obstante, para este mismo senador, entre las distintas soluciones que cabían, el Reglamento que el Pleno debatía había optado por una postura intermedia, equidistante entre una base partidaria pura y una representación exclusivamente territorial.

tico se publicó una útil enumeración concordada de las mismas, que fue realizada por M. ${ }^{a}$ Victoria García Atance (págs. 245-252).

${ }^{11}$ El Informe de la Ponencia se encuentra en el BOCE, Senado, I Legislatura, númeto 13 (e), 1 junio 1981 .

${ }_{12}$ BOCE, Senado, İ Legislatura, núm. 13 (f), 29 abril 1981. 
Mucho más matizada fue, por el contrario, la intervención del senador Laborda Martín, del Grupo Parlamentario-Socialista, quien, reconociendo que la configuración de estos Grupos èra consecuencia del entrecruzamiento de las tensiones 'ideológicas' $y$ 'territoriales, que el Senado expresaba muy particularmente, advertía quue ningún Grupo-Parlamentario estaba'satisfecho de la solución aportada, que, creía, podría ser' modificada en el futuro.

- Con estas apreciaciones, vertidas con ocasión de la presentación del dictamen de la Comisión, se dio por zanjado el tema en sede plenaria, por cuanto la discusión ulterior de los artículos 32 y.33 no aporta ningún elemento novedoso ${ }^{13}$.

$\therefore$ Puede decirse, en suma, que la tramitación parlamentaria de los artículos $32 \cdot$ y. 33 del Reglamento estuvo imbuída'del deseo dé subordinar cualquier agrupamiento territorial a los partidos actuantes en la Cámara, deseo que se acentúa incluso durante el trábajo de la Ponencia, que incorpora las enmiendas del Grupo de. UCD, que resaltaban esa subordinación. El sómetimiento a los partidos políticos' y la consciencia de la necesidad de buscar, no obstante, algún tipo de representación territorial son los elementos definitorios' de los Grupos Territoriales y los que explican, a la postre, su naturaleza jurídica. Es cierto que esta vinculación a los partidos' se veía matizada por la referencia a las federaciones, coaliciones o agrupaciones electorales, pero, como veremos más adelante, entendemos que esta referencia es' más una cláusula de estilo que una apertura a formas nuevas de agrupación de los parlamentarios en el seno. de la Cámara.

\section{NATURALEZA JURIDICA DE LOS GRUPOS}

Nos encontramos, pues, ante un ente relativamente atípico tanto en su naturaleza y funciones com̌o en su posición dentro del conjunto de la Cámara. No es fácil, sin duda, entender la dualidad de regímenes agrupacionales en el seno del Senado, por lo que, para percibir su alcance político, parece necesario, ante todo, examinär con cierta minuciosidad su naturaleza jurídica para inducir, a partir de ésta, una categoría que engarce con las diversas teorías que ha producido el Derecho parlamentario a partir, principalménte, de la segunda: posguerra mundial. Para ello vamos a examinar sucesivamente, y por este orden, sus contornos subjetivos, objetivos y de actividad que tienen que conjugarse para su formación, la personalidad jurídica resultante y, en fin, cuál es la categoría parlamentaria que de ahí se infiere.

¿Es suficiente la mera concurrencia de voluntades para constituir un Grupo Territorial? Pata los Grupos Parlamentariós, esta concurrencia parece evidentea tenor del artículo 28.1 del Reglamento del Senado ( «los senadores que resuelven constituirse...»), pero, en cambio, para los Grupos Territoriales, la simple concurrencia no parece resultar súficiente por cuanto se precisa también. la intervención externa del portavoz del Grupo Parlamentario al que previamente están adscritos los senadores, quien suscribe con éstos la relación nomi-

${ }^{13} \mathrm{El}$ debate se encuentra transcrito en el Diario de Sesiones del Senado, sesión plenaria núm. 156, de 26 mayo 1982. 
nal que se deberá entregar a la Presidencia de la Cámara. No hay, por consiguiente, un acto que exprese la autonomía de la voluntad de los senadores, sino una autorización concedida por el Grupo Parlamentario al que se ha sometido previamente el senador y cuya disciplina ha acatado. Ello conlleva, a su vez, que no se pueda hablar de un acto de admisión ulterior de un senador por el Grupo Territorial, como ocurre en los Grupos Parlamentarios, cuyo portavoz da el visto bueno a las nuevas incorporaciones, sino que aquél se produciría, en todo caso, en virtud de la autoridad que ostenta el portavoz del Grupo Parlamentario, si bien la dicción literal del artículo 33 («con referencia expresa a [...] agrupación al que pertenezcan sus componentes») sugiere la imposibilidad de que se integren senadores independientes de toda afiliación partidaria. Se trata de una expresión sin duda desafortunada, introducida, como se ha visto ya, para acentuar la vinculación Grupo Parlamentario-Grupo Territorial, que, de aplicarse con rigor, llevaría al absurdo de que un senador independiente integrado en un determinado Grupo Parlamentario no podría formar parte de un Grupo Territorial, aun cuando contara con el consentimiento del portavoz.

Esta peculiaridad subjetiva nos proporciona un dato de indudable importancia. Menzella ha recordado acertadamente que en la formación de un Grupo Parlamentario el dato de su origen partidario tiene escasa relevancia, por cuanto la condición básica para su constitución no es tanto el partido como la con.currencia de voluntades modulada cuantitativamente para cumplir el límite numérico que suelen fijar los Reglamentos. En este sentido, el origen partidario de los parlamentarios es perfectamente indiferente (aunque en el Senado español juega como condicionante su artículo 27.3 y 4) y puede haber Grupos multipartidarios y Grupos independientes ${ }^{14}$. Ahora bien, esta regla general, que juega también en nuestras Cortes con la excepción señalada, quiebra totalmente para los Grupos Territoriales desde que el artículo 33 vincula expresamente a éstos con un partido del que deben proceder, devaluando el origen - provincial o autonómico- de sus miembros. Este dato subjetivo tendrá importancia, como veremos, a la hora de fijar la naturaleza de estos Grupos.

Esta vinculación partidaria, por otra parte, reaviva el tema de la disciplina interna del Grupo Territorial. Aunque ésta puede modularse en función de las previsiones específicas de los Reglamentos internos de cada Grupo Parlamentario y de cada partido, se plantean dos interrogantes, a saber: a) si la disciplina del Grupo Parlamentario alcanza directamente al Grupo Territorial, y b) si cabe un régimen de disciplina autónoma de este último. Ambas cuestiones se pueden responder de forma muy diversa, ya que, en último término, -dependen de los referidos Reglamentos internos del partido y del Grupo Parlamentario, pero sí se puede adelantar que, con independencia de lo que resulte de examinar el ámbito de autonomía de los Grupos Territoriales (de lo que se trata más adelante), los elementos subjetivos presentes en los artículos 33 del Reglamento de la Cámara y, más particularmente, la participación del portavoz

${ }^{14}$ A. Manzella, Il Parlamento, Bolonia, Il Mulino, 1977, pág. 32. En contra, Silvano "Tosi (Diritto parlamentare, Milán, Giuffrè, 1974, pág. 147), para quien el Grupo Parlamentario es consecuencia a posteriori de la vinculación a priori del parlamentario y su partido; también, en contra, A. Tesauro ( I I gruppi parlamentari», en Rassegna di diritto .pubblico, año 22, núm. 2, abril-junio, 1967, pág. 199). 
y la referencia expresa al partido de procedencia en el trámite constitutivo, permiten hacer pensar que el régimen general de disciplina del Grupo Parlamentario se extiende al Grupo Territorial en conjunto.

A esta autorización inicial hay que agregar, como elementos subjetivos, que el senador proceda de un,Grupo que esté integrado por parlamentarios elegi. dos o designados, por lo menos, por dos Comunidades Autónomas; que el Grupo Territorial conste como mínimo de tres parlamentario, $y$, en sentido negativo, que los senadores no formen parte de otro Grupo Territorial. Se plantea así la duda de si será posible formar Grupos Territoriales en el seno del Grupo Mixto que, a juzgar por el Informe de la Ponencia que justificó la inadmisión de la enmienda, número 52 , del senador Portabella Rafols ${ }^{15}$, no parece en modo alguno prohibido, ya que en este Grupo se dan los elementos orgánicos que inciden sobre los requisitos subjetivos fijados en los artículo 32 y 33 del Reglamento, a excepción de lo que ha dicho ya para los senadores independientes.

El único elemento objetivo que se detecta es el de la finalidad de representación territorial que señala el segundo párrafo del artículo 32 del Reglarnento, lo que configura un requisito objetivo, y no subjetivo, porque, amén de fijar la procedencia espacial de estos senadores, señala el marco objetivo por donde se desenvolverá la actividad del Grupo Territorial, a tenor de los artículos 43 y 85 del propio Reglamento.

Los elementos de actividad y procedimentales nos indican cómo la constitución del Grupo Territorial es necesariamente posterior a la del Grupo Parlamentario de donde proçeden sus miembros, pero, a diferencia de éste, no existe ningún plazo para su formación. En cuanto al procedimiento, es el mismo que el señalado en el artículo 28 para los Grupos Parlamentarios, con dos especialidades, a saber: que toda la tramitación se hace a través del Grupo Parlamentario y con el visto bueno de su portavoz, y que se exige la expresión de la formación política en la que están integrados sus miembros.

La organización del Grupo Territorial no ofrece, en principio, más peculiaridades que la de disponer de un «representante» en lugar de un portavoz, pero la parca regulación que ha establecido el Reglamento de la Cámara ofrece no pocas dudas. En primr lugar, la ubicación sistemática del artículo 34 del Reglamento ( «El Senado facilitará a los Grupos Parlamentarios una subvención...»), más las funciones que corresponden a los Grupos Territoriales, hace pensar que éstos podrían disfrutar de una subvención diferenciada de la que puedan recibir los Grupos Parlamentarios de donde aquéllos procedan. En todo caso, los medios materiales de que puedan disponer van dirigidos a actividades limitadas, como se verá más adelante, y la cuantía de las subvenciones, al ser proporcional a sus componentes, tampoco puede ser excesiva, si bien no parece ofrecer dudas que el complemento fijo atribuido a los Grupos Parlamentarios debe ser igualmente concedido a los Grupos Territoriales. Todo ello demuestra que el tema no está resuelto normativamente y que dependerá dela actitud que pueda adoptar la Mesa de la Cámara ante los Grupos Territoriales.

En punto a la organización de estos Grupos cabe dudar si les son de apli-

${ }^{15}$ BOCE, núm. 13 (e), cit., pág. 193. 
cación los principios de autonomía que establece el artículo 27.5 del Reglamento, para los Grupos Parlamentarios, lo que enlaza, a su vez, con el problema de la vinculación jurídica con los partidos políticos. En realidad, ambas cuestiones van conexionadas. Formalmente, la relación Grupo Parlamentario/ Grupo Territorial podría agotarse con su constitución, cuando el portavoz del Grupo Parlamentario suscribe la relación nominal que se entrega, a través de éste, a la Presidencia de la Cámara. Desde ese momento podría ser de aplicación el artículo 27.5 del Reglamento en orden a su funcionamiento interno (aprobación de un Reglamento de régimen interno, asignación de funciones específicas a cada senador, etc.). Externamente, sin embargo, la relación entre ambas categorías de Grupos persiste, pues la participación de los representantes de los Grupos Territoriales en la Junta de Portavoces está supeditada a la voluntad del portavoz respectivo (art. 43.2), y su participación en los Plenos requiere el consentimiento de éste. Resulta, pues, de todo ello que es difícil entender, en perspectiva jurídica, que los Grupos Territoriales gocen de otra autonomía que la estrictamente autoorganizativa, y aún ésta está limitada, por un lado, por la tutela que ejerce el portavoz del Grupo Parlamentario (artículos 43 y 85 del Reglamento), y, por otra parte, por las previsiones del Reglamento interno del Grupo Parlamentario al que están sometidos los senadores del Grupo Territorial en cuanto miembros del Grupo Parlamentario ${ }^{16}$.

Esta última conclusión nos lleva directamente a examinar sus fuentes normativas en el Derecho vigente. Estas se reducen, en principio, a cuatro: el Reglamento del Senado, el-Reglamento interno del Grupo Parlamentario, los Estatutos del partido y el Reglamento interno específico de que pueda dotarse el Grupo Territorial. Mortati sostiene que, en cuanto entes autónomos, los Grupos Parlamentarios pueden llegar a tener una relación de Derecho privado con sus miembros ${ }^{17}$, lo que permitiría, en nuestro caso, tomar el conjunto del ordenamiento jurídico-privado como fuente normativa de los Grupos Territoriales. Sin entrar en la polémica desatada a partir de la famosa sentencia del Tribunal romano de 29 de abril de $1960^{18}$, cabe sostener que esta relación de Derecho privado alcanza tanto a los hipotéticos elementos no parlamentarios de su estructura: empleados, proveedores, etc., como a sus propios miembros, que, por ministerio del artículo 33 del Reglamento de la Cámara, tienen, en cuanto miembros de un partido, una relación jurídica privada con éste, como se desprende, a sensu contrario, de la sentencia 10/1983, de 21 de febrero, del Pleno del Tribunal Constitucional (Fund. jurídico tercero).

Peto junto a las fuentes de Derecho público y el conjunto del ordenamiento privado, se debe señalar a la Constitución, cuya única referencia a los Grupos Parlamentarios, el artículo $78.1^{19}$ no prejuzga la configuración de ésta. A esta

${ }^{16}$ A esta conclusión llega también E. Alvarez Conde en las breves líneas que dedica a estos órganos en El régimen político español, Madrid, Tecnos, 1983, pág. 154. También Fernández Segado, op. cit., págs. 101-102.

${ }^{17}$ C. Mortati, Istituzioni di diritto publico, vol. I, 9. ${ }^{2}$ ed., Padone, Cedam, 1975, página 509. Lo que lleva a Giuseppe Ugo Rescigno («Gruppi Parlamentari», en Enciclopedia del diritto, vol. 19, Milán, Giuffrè, 1970, págs. 794795) a negar el carácter de órgano de la Cámara de los Grupos Parlamentarios.

${ }_{18}$ Véase, por todos, $P$. Rescigno, "L'attivitá de diritto privato dei gruppi parlamentari», en Giurisprudenza costituzionale, año 6, fasc. 1961.

${ }^{19}$ Está un tanto extendido en la doctrina que los artículos 20.3 y 99.1 se refieren tam- 
fuente básica hay que añadir además, los usos, convenciones y costumbres parlamentarias, que pueden tener incluso ulterior expresión normativa en virtud de lo que dispone el artículo $37: 7$ y 8 del Reglamento de la Cámara. Como veremos más adelante, esta fuente consuetudinaria tiene particular relevancia para la futura funcionalidad de los Grupos Territoriales ${ }^{20}$.

Con este conjunto de elementos se puede llegar a determinar la personalidad jurídica de los Grupos Territoriales. Lo primero que se plantea, a este respecto, es su naturaleza pública o privada, tema ésta que ningún autor que se precie ha dejado de tratar siempre con nuevos matices personales ${ }^{21}$. Es indudable que la respuesta que se dé va vinculada al tema, de no menos actualidad en la doctrina española, de la personalidad del Estado y de las Cortes Generales, pero se pueden avanzar algunos elementos de clarificación si examinamos si los Grupos Territoriales; y aun los Grupos Parlamentarios, poseen naturaleza jurídico-pública. A este respecto, no vale ya, como recordaba Latournerie, comisario del Gobierno, con ocasión del arrêt Etablissements Vezia, apoyarse en una lista interminable y a veces inconexa de actividades públicas ${ }^{2}$, pues puede ser más operativo buscar un concepto doctrinal 'general, corno el de Garrido Falla, para quien el criterio fundamental para saber si existe una persona de Derecho público es su encuadramiento en la organización estatal ${ }^{23}$. Este criterio es suficiente, por el momento, para entender que, por exclusión; los Grupos Territoriales del Senado carecen de personalidad jurídica pública, como se prueba con el artículo 38 del Código Civil, pues la capacidad patrimonial contractual y procesal de aquéllos no está sometida al Derecho administrativo de acuerdo con el artículo $30^{\circ}$ de la Ley Reguladora de la Jurisdicción Contencioso-Administrativa. Pero hay más: la capacidad civil de' estos Grupos no viene en modo alguno regulada por la ley que los ha reconocido, es decir,

bién a los Grupos Parlamentarios, lo que es totalmente inexacto, como la propia redacción de ambos preceptos muestra, a poco que se lean atentamente. La práctica constitucional, por otra parte, ha venido a mostrar lo errónea que es esta interpretación, pues si el artículo 99.1 de la Constitución se refiere a Grupos Parlamentarios y no a grupos políticos con representación parlamentaria, el rey llamaría a consulta a un representante del Grupo Mixto del Congreso.

${ }_{20}$ Véase, en general, Giuseppe Ugo Rescigno, Le Convenzioni costituzionali, Padova, Cedam, 1972.

${ }^{21}$ Para no entrar en la extensa polémica suscitada, basta citar a Claudio Rossano, Partiti e Parlamento nello stato contemporaneo, Nápoles, Eugenio Jovene, 1972, págs. 285300, y A. Torres del Moral, «Los Grupos Parlamentarios», en Revista de Derecho Politico, núm. 9, primavera 1981, págs. 58-63. Ambos autores recogen todas las posiciones doctrinales con concisión y claridad.

${ }_{22}$ Arrêt Establissements Vezia, Consejo de Estado, 20 diciembre 1935, recogido en M. Long, P. Weil y G. Braibant, Les grands arrêts de la jurisprudence administrative, 7.² ed., París, Sirey, 1978, pág. 237.

${ }^{23}$ F. Gartido Falla, Tratado de Derecho administrativo, Madrid, Centros de Estudios Constitucionales, 1980, reimp. de la 7." ed., vol. I, pág. 363. Véase, en esta misma dirección, las interesantes consideraciones de J. Guasp (Derecho, Madrid, Gráficas Hergón, 1971, págs. 459-469), que establece, como nota explicativa de lo jurídico público, la idea de organización concebida como distribución de capas, estratos o sectores diferenciados según una consideración esencial jerárquica. Recientemente ha sido el propio Garrido Falla («Reflexiones sobre una reconstrucción de los límites formales del Derecho administrativo español», en Revista de Administración Pública, núm. 97, enero-abril 1982, págs. 7.30) quien se ha preguntado sobre la existencia de un Derecho administrativo parlamentario. Sus atinadas conclusiones vienen a corroborar, según creemos, la dificultad de incardinar 
el Reglamento de la Cámara, sino por sus Estatutos (art. 37 del Código Civil), que no tienen tampoco naturaleza jurídico pública si recordamos la antes citada sentencia 10/1983, del Pleno del Tribunal Constitucional. Hay que recordar, por último, que la constitución de los Grupos Territoriales no obedece a ningún acto de imperium de los poderes públicos, sino a la confluencia de dos tipos de voluntades, la de los senadores y la del Grupo Parlamentario a que pertenecen, a través de su portavoz. Todo ello, por supuesto, no obsta para que esta personalidad de Derecho privado sea de interés público, pues el criterio del interés no tiene como referencia el régimen jurídico que enmarca su existencia, sino el lucro o ganancia que se persigue en sus fines.

Estamos, pues, ante una personalidad de Derecho privado que, sin embargo, es imperfecta. La noción de persona jurídica exige, para perfeccionar su naturaleza, que el orden jurídico parcial que expresa alcance el mayor número posible de elementos configuradores de una determinada conducta. Si faltan los elementos más esenciales, estamos ante una persona jurídica imperfecta, que carece de independencia plena para regular su conducta ${ }^{24}$. En este supuesto, el Código Civil señala como elementos esenciales para conformar la personalidad jurídica el interés, sea público o particular; una organización interna que puede venir de las leyes, de la Administración o de sus Estatutos; la capacidad jurídica y de obrar, y el patrimonio propio. Estos elementos, en los Grupos Territoriales, no van adheridos automáticamente a su personalidad, sino que, como hemos observado, se vinculan a un órgano externo como es el Grupo Parlamentario, por lo que se debe concluir en que, al ostentar una titularidad limitada de derechos, obligaciones y capacidad jurídica, estamos ante una personalidad de Derecho privado imperfecta.

El examen de los elementos subjetivos, objetivos y de actividad que concurren en la constitución de los Grupos Territoriales, más el descubrimiento de sus fuentes normativas y los rasgos de su personalidad jurídica nos proporciona elementos suficientes para apuntar cuál es la naturaleza jurídica de estos órganos. Para ello conviene dejar de lado las teorías clásicas adelantadas, con tanta polémica, sobre los Grupos Parlamentarios, pues parece claro que ni las limitadas funciones que les son atribuidas por el artículo 32.3 del Reglamento (cuyo pormenor examinamos a continuación) permite su calificación como órganos de la Cámara (ni, por consiguiente, del Estado) ni tampoco parecen ser órganos de partido, desde el momento en que, en su constitución, confluyen la voluntad de sus miembros y la del Grupo Parlamentario en que están encuadrados, pero en modo alguno el del partido. Cierto es que los términos del artículo 33 del Reglamento añaden, como hemos visto, una referencia partidaria que está ausente en el artículo 28 , y que, por otra, mediatamente, se presupone una disciplina partidaria en sus miembros que podría llegar, incluso, a que los Estatutos de un partido regularan las relaciones y el sometimiento de sus diversos Grupos Territoriales a los órganos del partido. Pero, según

a los Grupos Parlamentarios en el campo del Derecho público. En la misma línea, con interesantes matizaciones, F. Santaolalla, Derecho parlamentario español, Madrid, Ed. Nacional, 1984, págs. 104-106.

24 Véase F. de Castro, La persona jurídica, Madrid, Civitas, 1981, espec. págs. 266-273, quien, no obstante, advierte contra la aceptación iconoclasta del concepto de persona juridica imperfecto que predomina en la legislación española. 
entendemos, estos elementos no son suficientes para ver en el Grupo Territorial un órgano del Partido.

En efecto, el factór determinante para la constitución del Grupo Territorial radica en la confluencia de voluntades parlamentario/Grupo Parlamentario, y sólo esta concurrencia perfecciona su naturaleza. Pero, una vez constituido (y es políticamente admisible que en esta concurrencia de voluntades influya decisivamente la voluntad de los órganos de dirección del partido), la competencia que puede corresponder al Grupo Territorial viene atribuida no por el partido, sino por el Reglamento, como nos enseña el artículo 32.3 de esta norma. Desde el punto de vista de la legislación española sobre partidos políticos, la concepción del Grupo Territorial como órgano del partido resulta aún más endeble. Así, tenemos que, de acuerdo con el artículo $4 .^{\circ}$ de la Ley 54/1978, de 4 de diciembre, son los Estatutos de cada formación partidaria los que deben regular su organización y funcionamiento, pero esta potestad autoorganizativa y autonormativa -que no es sino manifestación de poder y poder de crear normas dentro de los límites establecidos por la ley, como dice Luigi Ferri ${ }^{25}$ es de difícil ajuste con la ordenación establecida por el Reglamento del Senado, cuyo artículo 32.3 delimita los supuestos a través de los que discurre la actividad del Grupo Territorial. De ahí que sea difícil calificar como órgano de partido a un ente cuyas funciones han sido fijadas por un poder ajeno al partido y cuyos requisitos subjetivos y objetivos caen fuera de la esfera de autonomía del partido. Por eso, como recuerda Manzella, no es lo mismo formar parte de un ordenamiento jurídico que formar parte de la organización estructural de ese ordenamiento ${ }^{26}$, y aunque el impulso de la actividad del Grupo Territorial proceda, mediatamente, del partido, con lo que de alguna manera se integra en su ordenamiento, lo cierto es que, por imperativo del Reglamento de la Cámara, el Grupo no se puede integrar en la organización partidaria, que carece de potestad para fijar el marco de actividad de éste.

Estos mismos elementos contribuyen, por el contrario; a configurar el Grupo Territorial como un órgano del Grupo Parlamentario que, a diferencia de otros posibles órganos (gabinetes técnicos, comités de dirección etc.) tiene relevancia jurídico-parlamentaria. Es, pues, un órgano de proyección exțerna, reglamentariamente reconocida, del Grupo Parlamentario, de carácter ordinario - pues coadyuba regular, y no esporádicamente, en las funciones de éste-, pero que, sin embargo, no es un órgano necesario ${ }^{27}$, porque las funciones constitucional y reglamentariamente atribuidas a la. Cámara no precisan el concurso del Grupo Territorial. Y es órgano del Grupo Parlamentario porque, como hemos visto, tanto en su constitución como en su régimen disciplinario, fuentes y funciones, carece de autonomía, antes al contrario, está sometido inmediatamente al Grupo Parlamentario.

Esta calificación parte del supuesto de que el Grupo Parlamentario tenga naturaleza y origen partidario, si bien no es el único supuesto previsto en el

\footnotetext{
gina 8.

${ }^{25}$ L. Ferri, La autonomía privada, Madrid, Ed. Revista de Derecho Privado, 1969, pá-

${ }^{26}$ Manzella, Il Parlamento, cit., págs. 41-42.

27 Sobre el concepto de órgano parlamentario necesario, véase Mortati, op. cit., vol. 7 , págs. 506-507. Sobre la necesariedad de los Grupos Parlamentarios en el ordenamiento parlamentario español, véase Lucas Murillo, op. cit., pág. 138.
} 
artículo 33 del Reglamento de la Cámara, que alude, como se ha visto a federaciones, coaliciones o agrupaciones electorales. Ello no obstante, a efectos jurídicos, las consecuencias de que un Grupo Territorial se forme en el seno del Grupo Parlamentario de una federación, coalición o agrupación electoral son semejantes a las que derivan del carácter meramente partidario del Grupo Parlamentario. En términos políticos, por otra parte, tampoco se observan grandes diferencias, puesto que la finalidad última del precepto es reservar la vinculación del . Grupo Territorial con la entidad política bajo la que concurrió a la elección, sea ésta un partido, una coalición o una mera agrupación de electores. Resulta de ello, en definitiva, la persistencia del vínculo senador/ intermediario político, en detrimento de los nexos territoriales de los parlamentarios.

\section{FUNCIONES DE LOS GRUPOS PARLAMENTARIOS}

El análisis funcional de los Grupos Territoriales ha de deslizarse a través de dos puntos de referencia: positivo, el primero, que es la atribución específica de competencia que realiza el artículo 32.2 del Reglamento de la Cámara y, a través de este precepto, por medio de los artículos 43 y 85 de la misma norma; negativo el otro, que se expresa con el artículo 78.1 de la Constitución cuando prevé la representación proporcional de los Grupos Parlamentarios en las respectivas Diputaciones Permanentes de cada Cámara. Este punto de referencia negativa posee indudable importancia si la ponemos en conexión con el capítulo tercero del título tercero del Reglamento del Senado - que no prevé la participación de los Grupos Territoriales en la composición de la Diputación-, pues nos revela que, una vez conformada reglamentariamente la naturaleza y funciones de los Grupos Parlamentarios, los Grupos Territoriales quedan desprendidos del régimen constitucional establecido en el artículo 78.1 de nuestra norma fundamental, y, por ende, resultan desalojados de las funciones parlamentarias definidas en los títulos III, IV y $\mathrm{V}$ de ésta ${ }^{28}$, lo que no tendría que haber ocurrido necesariamente si el Reglamento del Senado se hubiera orientado en otra dirección, pues dentro del ámbito de la reserva reglamentaria - que, para Punset, se reconduce acertadamente al artículo 66.2 de la Constitución ${ }^{29}$-, era posible insertar a los Grupos Territoriales en el ejercicio pleno de las competencias de la Cámara.

Debemos examinar, por ello, las funciones expresamente atribuidas a estos entes por el Reglamento de la Cámara, y a continuación, las que se derivan del ordenamiento parlamentario sin tener un específico reconocimiento.

Las funciones expresas de los Grupos Territoriales han sido establecidas, como se ha visto, en el artículo 32.3 del Reglamento de la Cámara, que se remite, para su concreción, a los artículos 43 y 85 del mismo. Hay que destacar, de entrada, el carácter excepcional de esta atribución de competencias, ya

${ }_{28}$ Acerca de estas funciones, véase, en general, A. Manzella, «Las Cortes en el sistema constitucional español», cit., págs. 478-500. También Santaolalla, op. cit., págs. 191-211.

${ }^{29}$ Lo que no quiere decir, como afirma Alvarez Conde, que los. Grupos Territoriales acudan a la Junta sin calidad de miembros. Son, en realidad, parte integrante de los miembros de este órgano (op. cit., pág. 148). 
que en ningún precepto del capítulo segundo del título segundo encontramos la menor referencia a las funciones de los Grupos Parlamentarios, pues se presume que ostentan la titularidad de las que, expresa o tácitamente, se fijan en todo el Reglamento. Por el contrario, respecto a los Grupos Territoriales, juega la presunción inversa: sólo tienen la titularidad de las que reglamentariamente se fijan. Tenemos así, de entrada, que los Grupos Territoriales no tienen atribuida la totalidad de las funciones que despliegan los Grupos Parlamentarios, por lo que su posición se encuentra inicialmente minuscapacitada.

Al ser tal artículo 32.3 una mera norma de remisión, no tiene sentido comentarlo, por lo que conviene examinar, en primer lugar, el artículo $43 \mathrm{del}$ Reglamento. De acuerdo con este precepto, a las reuniones de la Junta de Portavoces podrán asistir dos representantes de los Grupos. Territoriales de un mismo Grupo Parlamentario, designados por su portavoz. Y si se ha de deliberar sobre una materia que afecte especialmente a una Comunidad Autónoma, el presidente de la Cámara lo comunicará a los portavoces de aquellos Grupos Parlamentarios en los que existieren Grupos Territoriales a fin de que también puedan asistir representantes de estos últimos.

Tenemos, por consiguiente, que son dos los supuestos regulados en este precepto. En primer lugar, el régimen ordinario de reuniones de este órgano, y en segundo, aquél que corresponde a la deliberación de una materia que afecta a una determinada Comunidad Autónoma, a juicio, según se infiere del artículo 43.1, que atribuye la potestad de convocatoria al presidente de la Cámara, de este último. Se trata de dos supuestos completamente distintos en punto a su eficacia política (que no jurídica) y a su régimen de convocatoria, por lo que conviene examinarlos por separado.

En el primer caso se observa con mayor intensidad la cualidad del Grupo Territorial como mero órgano del Grupo Parlamentario, y ello porque la asistencia se realiza por iniciativa del Grupo Parlamentario a través de su portavoz, que está facultado para determinar el núméro de asistentes por'cada Grupo Parlamentario («hasta dos...»); la procedencia de los mismos, cuando se han constituido más de dos Grupos Territoriales en el seno del Parlamento, y hasta la oportunidad de la propia asistencia, sin que la Presidencia de la Cámara o cualquiera de sus órganos tenga atribuciones sobre estos extremos. Por otra parte, la inasistencia de representantes de Grupos de la totalidad de las Comunidades Autónomas (aun cuando puedan existir en la Cámara) aminora la representación especial de que podría dotarse la Junta, lo que conduce a una función de mero asesoramiento de cada portavoz ${ }^{30}$. A ello debe añadirse, por último, que la imposibilidad de que los Grupos. Parlamentarios ostenten la iniciativa para solicitar la conviocatoria de la Junta, como así ocurre en el Congreso, resta dinamismo a los Grupos Territoriales, que, a través de los Grupos Parlamentarios, podrían instar de consuno una reunión para determinados trámites de interés autonómico.

En el segundo de estos supuestos se puede detectar un matizadísimo giro en favor del protagonismo de los Grupos Territoriales, pues es posible la asistencia de la totalidad de los que representan a una Comunidad Autónoma,

${ }^{30}$ Lo que no quiere decir, como afirma Alvarez Conde, que los grupos territoriales acudan a la Junta sin calidad de miembros. Son, en realidad, parte integrante de los miembros de ese órgano (op. cit., pág. 148). 
por medio de sus representantes, con lo que parece que estamos ante la única ocasión en que su actividad no parece depender de los Grupos Parlamentarios, aunque sea a través de éstos como se tramita la convocatoria del presidente de la Cámara. Aún así, como se ha advertido anteriormente, no hay que olvidar que, en todo caso, es el presidente el que califica si una materia afecta especialmente a una Comunidad. Además, una vez que asisten los Grupos Territoriales a la Junta, se entra en el régimen común, que regula las sesiones (voto ponderado, etc.), por lo que esta asistencia no produce efectos jurídicos especiales.

La escasa relevancia y dinamicidad de los Grupos Territoriales en la Junta de Portavoces procede, sin embargo, de la ordenación que el Reglamento de la Cámara ha dado a la Junta de Portavoces. En el Derecho comparado, y también en el Reglamento del Congreso de los Diputados, la Junta de Portavoces - Conferencia de Presidentes suele ocupar una posición de cierta relevancia constitucional, bien por su capacidad para autoconvocarse automáticamente o por iniciativa de algunos Grupos Parlamentarios (art. 12 del Reglamento del Consejo Nacional suizo y art. 39.1 del Reglamento del Congreso de los Diputados español, respectivamente), bien por su competencia para fijar el calendario de trabajo o el orden del día de las sesiones, cuyo acuerdo suele ser necesario (art. 6..$^{\circ}$ del Reglamento del Consejo de los Estados suizo, art. 23 del Reglamento de la Cámara de Representantes belga y art. 67.1 del Reglamento del Congreso de los Diputados español). La Junta de Portavoces de nuestro Senado se sitúa en uno de los niveles más bajos de la escala, que permitiría medir la competencia de estos órganos, por cuanto carece de competencia para reunirse a propuesta de los Grupos y sus funciones; a excepción de las fijadas en los artículos 76 y 136, son de mera audiencia, con lo que estamos, como ha dicho Tosi para la de la Cámara de los Diputados italiana, ante un colegio imperfecto que carece de potestad de convocatoria y para determinar su orden del día ${ }^{31}$. De ahí que si sumamos, por una parte, la carencia de personalidad y autonomía de los Grupos Territoriales para impulsar el funcionamiento de la Junta, y, por otro lado, la reducida relevancia institucional de ésta, podemos concluir en que esta función tiene escasa proyección política, por el momento.

La segunda función expresamente prevista en el Reglamento de la Cámara se halla regulada en el artículo 85 del mismo. En los debates plenarios sobre cuestiones que afecten «de modo especial» a una o varias Comunidades Autónomas, el presidente de la Cámara, «de acuerdo con los portavoces» de los Grupos Parlamentarios respectivos», ampliará el turno de portavoces para que puedan intervenir los representantes de los Grupos Territoriales aceptados, si bien, «en caso necesario», el presidente podrá limitar el número y duración de estas intervenciones. Como puede observarse, la intervención de estos Grupos Territoriales aparece sometida a toda clase de cautelas e imprecisiones. En primer lugar, se trata de una potestad del presidente, que resulta escasamente reglada, pues es el único órgano competente para calificar un concepto indeterminado como el de «modo especial». En segundo lugar, corresponde al portavoz del Grupo Parlamentario otorgar su acuerdo a la intervención del Grupo

${ }^{31}$ Silvano Tosi, op. cit., págs. 214-215. 
Territorial y; una vez otorgado, reaparece el presidente de la Cámara con su poder de dirección de los debates, en cuyas funciones hay que alojar la limitación del número y duración de estas intervenciones.

Nos encontramos, en definitiva, ante una facultad de difícil inserción en el cuadro de derechos de disfrute colectivo en è seno de la Cámara, al estilo de los que regulan los artículos 70,107 o 120 del Reglamento, por ejemplo. Por el contrario, es una facultad sometida a la discrecionalidad de los órganos de la Cámara que, para mayor imprecisión, se ubica en la normativa de la ordenación de los debates, por lo que su encaje específico en una determinada categoría procedimental (procedimiento legislativo, relaciones con otros órganos, etc.) queda en la nebulosa.

Al lado de las funciones expresamente recogidas en el Reglamento, parece probable que los Grupos Territoriales, participando como tales, puedan actuar en determinados procedimientos cuyo ejercicio es de titularidad individual de los senadores. Siguiendo la sistemática del Reglamento del Senado podemos indagar sobre la participación de estos Grupos en: a) la organización de la Cámara; $b$ ) el procedimiento legislativo, y. $c$ ) el control sobre el ejecutivo.

En punto a la organización de la Cámara, partimos de una circunstancia certeramente señalada por Punset, a saber: que los Grupos Parlamentarios carecen de todo relieve en el funcionamiento de esta Cámara en beneficio de una mayor autonomía de los órganos rectores de la misma ${ }^{32}$. Aun así, de modo general, podemos señalar que la facultad para proponer el establecimiento de comisiones de investigación o especiales «para realizar encuestas o estudios sobre cualquier asunto de interés público», como reza el artículo 59.1 del Reglamento, abre un interesante campo que se complementa, como veremos más adelante, con el posible juego autonómico que podría dar la Comisión Legislativa de Autonomías y Organización y Administración Territorial. En el terreno legislativo, el Reglamento ha establecido un conjunto de procedimientos en los que la iniciativa o el impulso corresponden, por igual, a los Grupos Parlamentarios y a los senadores individuales, generalmente en número de veinticinco. Tales actuaciones son: la presentación de enmiendas o propuestas de veto a los proyectos y proposiciones de ley (art. 107.1); la formulación de proposiciones de ley (art. 108.1); las propuestas para que la Cámara o el Congreso decidan si un convenio intercomunitario necesita o no autorización de las Cortes Generales (art. 137.2); la presentación de una propuesta para que el Senado aprecie la necesidad de dictar leyes de armonización (art. 141.1), y, en fin, la propuesta para que la Cámara requiera al Tribunal Constitucional para que declare acerca de la constitucionalidad de un tratado o convenio (artículo 147).

En todos estos supuestos, los senadores no precisan el visto bueno del portavoz de su Grupo Parlamentario, sino que se trata de una tramitación jurídica que atenúa la crisis del mandato representativo en el constitucionalismo contemporáneo, crisis a la que se ha referido el profesor Torres del Moral, recordando sus manifestaciones más llamativas (la adscripción individual o partidaria del escaño, etc. ${ }^{33}$. Estamos, pues, ante unos supuestos en donde la

${ }^{32}$ Punset, op. cit., págs. 134-135.

33 A. Torres del Moral, «Crisis del mandato representativo en el Estado de partidos», en Revista de Derecho Político, núm. 14, verano 1982, págs. 7-30. 
relación senador/Grupo Parlamentario se diluye frente a la emergencia de iniciativas personales de cada parlamentario y, precisamente, éstas son orientables en dirección al reforzamiento de la participación de los Grupos Territoriales en los diversos trámites legislativos, pues no está reglamentariamente prohibido que cualquiera de las iniciativas legislativas reseñadas se tramite con la firma de los senadores y una referencia expresa al Grupo Territorial al que están adscritos.

No obstante, tampoco se debe magnificar la incidencia de los Grupos Territoriales en la función legislativa, y ello por los mismos motivos, de índole externa a su regulación reglamentaria, que acabamos de ver respecto a su participación en la Junta de Portavoces. Es sabido, como ha recordado Manzella, que en la Constitución aspañola el Parlamento sólo cumple una función complementaria en el proceso normativo, que tiene que compartir con el poder ejecutivo y las Comunidades Autónomas. Función «organizadora de la legislación», predicable de las Cortes Generales ${ }^{34}$, que se acentúa aún más en sede senatorial por el predominio del Congreso de los Diputados (disminución de su capacidad opositora a los proyectos y proposiciones procedentes de la otra Cámara, plazo determinado para la tramitación, imposición externa del trámite de urgencia) ${ }^{35}$. Y si descendemos a los institutos parlamentarios específicos, veremos que, en lo que se refiere al trámite de enmiendas, el Reglamento del Senado, aunque más atenuadamente que en el Congreso, contiene diversos mecanismos para diluir su debate si lo considera oportuno o necesario el presidente de la correspondiente Comisión o el de la Cámara (arts. 114.3, 116, 121 y 124). Por último, no se debe olvidar que el parlamentarismo racionalizado que la Constitución configura restringe sumamente la iniciativa legislativa que no dimana del ejecutivo ${ }^{36}$. Por todas estas consideraciones, el margen relativamente extenso que el Reglamento del Senado abre implícitamente a los Grupos Territoriales queda reducido por imperativos constitucionales.

Por lo que se refiere a los instrumentos ordinarios de control sobre el ejecutivo ${ }^{37}$, los senadores tienen derecho, individual o colectivamente, según los casos, a formular preguntas e interpelaciones al Gobierno, así como a presentar mociones ordinarias o incidentales (arts. 160, 170, 175 y 180 del Reglamento), pero los diversos institutos de los que se pueden valer se enmarcan,

${ }^{34}$ Manzella, «Las Cortes en el sistema...», cit., págs. 483-487. En contra, Ignacio de Otto, «La función política de la legislación», en M. A. Aparicio, Parlamento y sociedad civil, Barcelona, Universidad de Barcelona, 1980, para quien «el poder constituyente ha minimizado las funciones de control y creación del órgano parlamentario y lo ha reducido a la función legisladora» (pág. 49).

${ }_{35}$ Véase Alvarez Conde, op. cit., págs. 177-179; Santamaría Pastor, «Artículo 90», cit., in totum.

${ }_{36}$ Véase Punset, «La iniciativa legislativa en el ordenamiento español», en Las Cortes Generales..., cit., págs. 241-259.

${ }^{37}$ Utilizamos este término dándole un pleno contenido jurídico. Después de la sugestiva monografía de Fernando Santaolalla, El Parlamento y sus instrumentos de información, Madrid, Edersa, 1982, parece obligado examinar con precaución las categorías hasta ahora utilizadas por influjo de la politología francesa. Aun así, el estudio atento del Reglamento del Senado, y particularmente sus artículos 167.2 y 173, nos revela que las preguntas y las interpelaciones se configuran como algo distinto de unos institutos destinados a la mera reclamación de información, ya que concluyen en actos sancionatorios de una intensidad quizá leve, pero efectiva. 
como hemos visto anteriormente, en un sistema de bicameralismo desigual ${ }^{38}$, que hace muy problemático el ejercicio de la función de control reconocida por el artículo 66.2 de la Constitución, como ha visto el profesor Portero ${ }^{39}$. Dentro de este marco insuficiente, la acción de control de los Grupos Territoriales puede desenvolverse con intensidad no inferior a la de los Grupos Parlamentarios.

\section{LOS GRUPOS TERRITORIALES Y LA ARTICULACION AUTONOMICA}

DEL SENADO

Al llegar a este punto parece necesario avanzar dos conclusiones provisionales, a saber: a) la naturaleza jurídica del Grupo Territorial es la de un órgano del Grupo Parlamentario, con personalidad imperfecta y de Derecho privado, aun cuando de interés público; $b$ ) las funciones expresamente atribuidas al Grupo Territorial por el Reglamento del Senado denotan, por su limitado ámbito, esa naturaleza de órgano de otro órgano, y. si bien dicho ámbito es. ampliable en dirección a otras funciones que se désprenden implícitamente del Reglamento, la posición que ocupa el Senado dentro del juego de órganos constitucionales reduce necesariamente su alcance funcional. Detrás de estas dos conclusiones se perfila con notable fuerza una interrogante: vistas las insuficiencias con que la Constitución configura el Senado de cara a su actuación como Cámara territorial, ¿pueden los Grupos Territoriales crear una dinámica parlamentaria que conduzca a una nueva ordenación institucional más sensible y mejor orientada al ejercicio de funciones de cuño territorial?

La interrogante, sin duda, no es ajena a las preocupaciones de la doctrina. Hace algún tiempo, cuando aún no se había aprobado el vigente Reglamento de la Cámara, el profesor Torres del Moral se preocupó de indagar la incidencia del carácter territorial del Senado en la regulación de sus Grupos Parlamentarios, y apuntó algunas muy interesantes ideas tomadas de la práctica del Parlamento europeo, ideas que en modo alguno ha retomado el Reglamento ${ }^{40}$. Con posterioridad a la aprobación de esta última norma, el profesor Santolaya Macchetti elaboró un cuadro de ingeniería constitucional sumamente sugestivo donde el Senado adquiere un notable protagonismo,como titular de las técnicas. constitucionales de cooperación internacional, y ello, precisamente, a través de una posible reestructuración de la Cámara a partir de la territorialización de los actuales. Grupos Parlamentarios, que en modo alguno parece vedado por la Constitución ${ }^{41}$..Ambos trabajos apuntan con acierto a la única clave que puede desbloquear las insuficiencias territoriales del Senado sin revisar la Constitución: la potenciación de sus Grupos Territoriales.

${ }^{38}$ Gonzalo, op. cit., págs. $659-660$.

${ }^{39}$ Portero, op. cit., págs. 229-231. Véase también P. Lucas Verdú, «El control por el Senado de la política gubernamental (¿responsabilidad política del Gobierno ante el Senado?)», en M. Ramírez (ed.), El control parlamentario del Gobierno en las democracias pluralistas, Barcelona, Labor, 1978, págs. 361-371, donde se apuntan los supuestos en queel Anteproyecto de Constitución favorecían el ejercicio del control político del Senado.

40 Torres del Moral, «Los Grupos Parlamentarios», cit., págs. 49-50.

41 . Santolaya Macchetti, Descentralización y cooperación, Madrid, Instituto de Estudios de Alministración Local (en prensa). 
Parece, por ello, que la simple, pero profunda, reforma del Reglamento de la Cámara podría aumentar notablemente la proyección autonómica del Senado. No vamos, sin embargo, a extendernos en esta dirección, por cuanto Santolaya Macchetti ya lo ha realizado con acierto. En cambio, en la perspectiva de lege lata, sin introducir reformas en el Reglamento, existen posibilidades de reorientar en sentido autonómico la Cámara a partir de una prudente utilización de convenciones o usos parlamentarios, que, asumidos y concertados por el Senado, podría producir cambios notables ${ }^{42}$.

Estos usos parlamentarios podrían introducirse en la Cámara sin conflicto, puesto que están reconocidos en el artículo 37.9 del Reglamento, cuya observancia se atribuye al presidente. A partir de esta colaboración de la Junta de Portavoces, en virtud de la facultad de ser oída para fijar las normas interpretativas o supletorias que dicte la Presidencia (art. 44,c), se podría diseñar una práctica que diera intervención a los Grupos Parlamentarios en las siguientes direcciones:

a) Generalización de los Grupos Territoriales. El punto de partida de esta nueva dinámica ha de ser, necesariamente, el compromiso de los Grupos Parlamentarios que representan a partidos de implantación estatal para constituir tantos Grupos Territoriales como sea reglamentariamente posible. El Grupo Parlamentario quedaría reducido a un órgano de coordinación y dirección política, donde estuvieran presentes los representantes de los Grupos Territoriales.

b) Territorialización de los órganos de la Cámara. Respetando la composición partidaria de los órganos, es posible establecer, dentro de cada Grupo Parlamentario, un sistema rotatorio mediante el cual tanto la Mesa como la Diputación Permanente sean elegidas de acuerdo con criterios territoriales, sabiéndose y haciéndose público los Grupos Territoriales a los que están adscritos los miembros de estos órganos.

c) Institucionalización de la presencia de los Grupos Territoriales en la Junta de Portavoces. Aplicado el segundo de los supuestos contenidos en el artículo 43.2 del Reglamento, parece aconsejable que el presidente califique con criterio sistemáticamente amplio las materias que afectan a las Comunidades Autónomas (¿qué materia no afecta, con mayor o menor alcance, a las autonomías territoriales a la vista del artículo 149 de la Constitución?), a fin de que los Grupos Territoriales puedan acudir regularmente a la Junta de Portavoces.

d) Transformación de los trámites del procedimiento legislativo, de modo que se establezca cualquiera de estas dos vías: o utilización de la competencia legislativa de la Comisión de Autonomías y Organización y Administración Territorial, aplicando para el debate lo previsto por el artículo 85 del Reglamento para el Pleno, o, con una interpretación

${ }^{42}$ Sobre las convenciones constitucionales y su especial proyección parlamentaria, contúltese O. Hood Phillips y Paul Jackson, Constitucional and Administrative Law, 6. ${ }^{a}$ ed., Londres, Sweet \& Maxwell, 1978, págs. 104-119, así como G. U. Rescigno, Le convenzioni..., cit., in totum. 
amplia del artículo 58 del Reglamento, tender a constituir Comisiones. conjuntas con participación de la referida Comisión de Autonomías.

e) Aplicación, como régimen general, del artículo 85 para las sesiones. plenarias, en cuyo caso habría que modular la ordenación de los Plenos en lo que al uso de la palabra se refiere, para lo que está facultada. la Presidencia por el artículo $37.7 ; 8$ y 9.

La propia naturaleza de los usos y convenciones parlamentarias impide. aplicar estos criterios de forma inmediata y simultánea, pero sí se va creando una dinámica autonómica en la Cámara, que no es incompatible con la esencia del mandato representativo ni con la composición partidaria de los Parlamentos contemporáneos (como lo prueba la Cámara de los Comunes, con sus Comisiones para Escocia, Gales e Irlanda del Norte), no resulta aventurado pensar que el bicameralismo imperfecto dejaría paso, sin fraude constitucional, a. la configuración de una Cámara más volcada, y no sólo legislativamente, a la. descentralización territorial ${ }^{43}$.

\section{CONCLUSIONES}

Primera. La regulación de los Grupos Territoriales en el vigente Reglamento del Senado pretende, como resulta de su tramitación parlamentaria, diferenciar a aquéllos de los Grupos Parlamentarios, vincularlos a los partidos y reducir su capacidad autoorganizativa mediante la transformación de sus portavoces en meros representantes.

Segunda. El examen de los elementos subjetivos, objetivos y de actividad inherentes a los Grupos Territoriales nos revela que estamos ante un órgano: que posee personalidad jurídica imperfecta, de Derecho privado y de interés público. Esta personalidad jurídica inserta a los Grupos Territoriales en los Grupos Parlamentarios, pues no basta la mera concurrencia de voluntad de los: senadores para constituirlos. Por ende, estamos ante un órgano del propio. Grupo Parlamentario, que no de la Cámara o de los partidos.

Tercera. Las funciones que pueden corresponder a los Grupos Territoriales se pueden clasificar en dos categorías; a saber: las expresamente previstas: por el Reglamento de la Cámara y aquellas otras que, por configurarse como derecho de participación individual de los senadores, pueden ejercitarse por los.

${ }^{43}$ Para esta última parte de la comunicación hemos tenido en cuenta las consideraciones de los profesores Aja y Arbos (op. cit., págs. 61-66) y Fernández Segado (op. cit., páginas 100-113). Sin embargo, los primeros redactaron el trabajo que citamos con anterioridad' a la aprobación del vigente Reglamento, con lo que se limitan a apuntar la necesidad de. dar una mayor dinámica territorial a la Cámara sin saber todavía cómo se configuratían los Grupos Territoriales. El segundo, que realiza un meritorio análisis de estos.Grupos, no intenta indagar su funcionalidad territorializadora, sino que apunta hacia determinadas medidas extrarreglamentarias que habrían de tenerse en cuenta cuando se resuelva iniciar la revisión constitucional. 
Grupos Territoriales en cuanto agrupación de parlamentarios. Las funciones expresas sólo pueden ejercitarse con autorización de los Grupos Parlamentarios o del presidente del Senado, según los casos. Paradójicamente, las funciones implícitas a la condición de senador podrían dar un cierto protagonismo a los Grupos Territoriales, pero su alcance resulta constitucionalmente limitado.

Cuarta. No obstante este limitado alcance funcional, una interpretación más ampliamente autonómica del Reglamento vigente que se apoyara en la paulatina utilización y consolidación de usos y convenciones parlamentarias, podría dar un mayor protagonismo a los Grupos Territoriales dinamizando territorialmente la Cámara para diferenciarla del Congreso de los Diputados. 